\title{
Factors influencing the implementation of Malaysia Sustainable Palm Oil (MSPO) among oil palm smallholders in Malaysia
}

\begin{abstract}
The oil palm industry in Malaysia plays an important role in the growth of the agricultural sector in this country through its contribution to the Gross Domestic product (GDP), foreign exchange, and employment. Oil palm demands are continual increasing as it can produce high yield and low production cost. The present study aimed to investigate the factors influencing the implementation of Malaysia Sustainable Palm Oil (MSPO) among the independent smallholders in Malaysia. The result observed several socio-economic factors that can lead to the implementation practices such as smallholder's age, perceived benefits of MSPO, smallholder's education level, Cost of MSPO, knowledge towards MSPO and government support of MSPO. Empirical data shows that there is a need to introduce policies that will guide palm oil smallholders towards sustainable production in order to sustain our oil palm industries in the global market. This study reveals the factors influencing the implementation of Malaysia Sustainable Palm Oil (MSPO) among the independent smallholders in Malaysia.
\end{abstract}

Keyword: Oil palm; Malaysia Sustainable Palm Oil (MSPO); Smallholders 